Annales Geophysicae, 23, 659-663, 2005

SRef-ID: 1432-0576/ag/2005-23-659

(C) European Geosciences Union 2005

\title{
Wavelet transforms of meteorological parameters and gravity waves
}

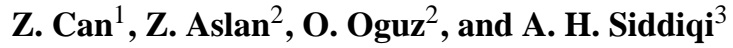 \\ ${ }^{1}$ Yildiz Technical University, Faculty of Science and Letters, Dept. of Physics, Istanbul, Turkey \\ ${ }^{2}$ Faculty of Engineering and Design, Istanbul Commerce University, Istanbul, Turkey \\ ${ }^{3}$ King Fahd University of Petroleum and Minerals, Department of Mathematical Sciences, Dhahran, Saudi Arabia
}

Received: 15 September 2004 - Revised: 21 December 2004 - Accepted: 13 January 2005 - Published: 30 March 2005

\begin{abstract}
The main purpose of this paper is to analyze some characteristics of gravity waves (GWs), and seasonal variations of atmospheric waves over Istanbul by using wavelet techniques. Daily radiosonda data of Istanbul in the troposphere and lower stratosphere $(1000 \mathrm{hPa}-30 \mathrm{hPa})$ between 1993 and 1997 have been considered. Wavelet analysis based on a computer simulation of data is generally close to the real data when Daubechies wavelet series are used. Daily, monthly, seasonal and annual variations of pressure heights, air temperature and deviations from mean values have been analyzed. Variations show the effects of gravity waves for different pressure levels in the troposphere. These waves lead to the meso-scale wave-form structures in spring, autumn and winter. As a result of this study, wavelet series and transforms for data construction, definition of some discontinuities and the local effects on the signal have been compared with the results of previous studies. The most similar structure between temperature, turbulence parameters and geopotential height deviations has been defined at the $500-\mathrm{hPa}$ pressure level.
\end{abstract}

Keywords. Atmospheric composition and structure (pressure, density and temperature) - Meteorology and atmospheric dynamics (convective processes; turbulence)

\section{Introduction}

Dynamics and thermodynamics of the lower atmosphere determine its physical conditions. Wind, temperature and humidity profiles have a crucial role in the growing and propagation of turbulence and internal gravity waves. Many experimental campaigns have been carried out to study the characteristics and effects of gravity waves in the lower, middle and upper atmosphere over the last decades (Isaac et al., 2004).

The wavelet transform was applied to the analysis of characteristics of thermal and velocity fields of coherent

Correspondence to: Z. Can

(zehcan@yildiz.edu.tr) structures from turbulence data taken within and above a deciduous forest by Gao and $\mathrm{Li}$ (1993). This study demonstrates the usefulness of wavelet analysis in decomposing structures at different scales, hidden in time series data. The wavelet technique is a useful tool for analyzing time series with many different time scales or changes in variance. A practical step-by-step guide to wavelet analysis is given with examples taken from time series of the El Niño-Southern Oscillation (ENSO) (Torrence and Compo, 1998).

Wavelet methods have been applied to the study of the stable atmospheric boundary layer under non-stationary conditions by Terradellas et al. (2001). Wavelet analysis is a useful tool to determine the dominant modes of the signal, as well as its evolution in time. It also provides easier detection of short duration events in large series.

Zink and Vincent (2001) described a technique to detect gravity wave packets in high-resolution radiosonde soundings of horizontal wind and temperature. A strong seasonal cycle in the total wave variance was found with a maximum in winter.

A calendar of the negative and positive phases of the North Sea-Caspian Pattern (NCP) for the period 1958-1998 was used to analyze the implication of the NCP upper level teleconnections on the regional climate of the eastern Mediterranean basin (Kutiel et al., 2002). The maximum impact of the NCP on mean air temperature was detected in the continental Anatolian Plateau, where the mean seasonal differences are around $3.5^{\circ} \mathrm{C}$. This influence decreases westwards and southwards.

A sudden temperature rise in the lower thermosphere can support surface waves propagating horizontally with energy concentrated near the sudden temperature rise (Ding et al., 2003). The energy distribution is shifted toward the lower atmosphere when compared with wave modes without winds. The descent of energy distribution makes the energy attenuation caused by viscosity and thermal conductivity drops down. This leads to the rise of attenuation distances.

The purpose of the present study is to understand the characteristics of lower atmospheric turbulent structure and 
Table 1. Seasonal average values of pressure height deviations between 1000 and $300 \mathrm{hPa}$ pressure levels.

\begin{tabular}{|c|c|c|c|c|c|}
\hline $300 \mathrm{hPa}(\mathrm{dh})$ & spring & summer & autumn & winter & annual \\
\hline 1993 & 125.86 & 95.04 & 115.76 & 115.37 & 124.30 \\
\hline 1994 & 120.76 & 79.67 & 64.57 & 105.08 & 99.72 \\
\hline 1995 & 130.42 & 58.27 & 136.63 & 172.43 & 78.49 \\
\hline 1996 & 119.6 & 76.32 & 121.79 & 169.92 & 105.13 \\
\hline 1997 & 129.79 & 84.60 & 106.32 & 90.82 & 133.62 \\
\hline mean & 125.29 & 78.78 & 109.01 & 130.72 & 108.25 \\
\hline \multicolumn{6}{|l|}{$500 \mathrm{hPa}(\mathrm{dh})$} \\
\hline 1993 & 87.81 & 57.75 & 70.05 & 79.27 & 84.76 \\
\hline 1994 & 80.05 & 53.15 & 42.37 & 73.13 & 66.93 \\
\hline 1995 & 80.76 & 35.37 & 85.48 & 66.22 & 70.78 \\
\hline 1996 & 79.73 & 51.75 & 76.73 & 66.54 & 69.62 \\
\hline 1997 & 91.69 & 51.88 & 72.72 & 55.51 & 87.11 \\
\hline mean & 84.01 & 49.98 & 69.47 & 68.13 & 75.84 \\
\hline \multicolumn{6}{|l|}{$700 \mathrm{hPa}(\mathrm{dh})$} \\
\hline 1993 & 60.26 & 32.57 & 45.06 & 54.63 & 58.99 \\
\hline 1994 & 54.03 & 40.10 & 28.46 & 54.09 & 47.60 \\
\hline 1995 & 47.19 & 25.54 & 49.91 & 46.93 & 45.10 \\
\hline 1996 & 54.20 & 33.41 & 50.40 & 44.8 & 47.53 \\
\hline 1997 & 56.87 & 53.84 & 46.90 & 41.63 & 51.69 \\
\hline mean & 54.51 & 37.09 & 44.15 & 48.42 & 50.18 \\
\hline \multicolumn{6}{|l|}{$850 \mathrm{hPa}(\mathrm{dh})$} \\
\hline 1993 & 48.93 & 25.77 & 32.42 & 46.16 & 42.38 \\
\hline 1994 & 38.56 & 30.20 & 37.31 & 50.58 & 40.09 \\
\hline 1995 & 36.89 & 23.70 & 41.83 & 50.52 & 40.60 \\
\hline 1996 & 44.22 & 25.31 & 39.61 & 43.88 & 40.81 \\
\hline 1997 & 47.11 & 28.5 & 38.70 & 48.65 & 39.72 \\
\hline mean & 43.14 & 26.70 & 37.97 & 47.96 & 40.72 \\
\hline \multicolumn{6}{|l|}{$1000 \mathrm{hPa}(\mathrm{dh})$} \\
\hline 1993 & 40.28 & 29.72 & 43.53 & 44.78 & 43.10 \\
\hline 1994 & 35.62 & 27.65 & 30.44 & 56.37 & 34.86 \\
\hline 1995 & 38.13 & 26.11 & 42.27 & 61.21 & 44.75 \\
\hline 1996 & 38.93 & 28.20 & 39.46 & 53.90 & 42.47 \\
\hline 1997 & 49.37 & 30.68 & 43.39 & 67.25 & 45.99 \\
\hline mean & 40.47 & 28.47 & 39.82 & 56.70 & 42.23 \\
\hline
\end{tabular}

internal gravity waves in the vicinity of Istanbul. The main objectives of this paper are listed below:

1. To define the variation of gravity wave characteristics in a time domain.

2. To apply 1-D-wavelet analysis and wavelet packets and to explain discontinuities in the daily variations of air temperature, pressure heights, thermal conductivity and viscosity.

3. To analyze seasonal variations of gravity waves by considering radiosonda data and to compare the results with the large-scale effects such as La-Niña and El-Niño.
Table 2. Seasonal average values of temperature deviations between 1000 and $300 \mathrm{hPa}$ pressure levels.

\begin{tabular}{|c|c|c|c|c|c|}
\hline $300 \mathrm{hPa}(\mathrm{dT})$ & spring & summer & autumn & winter & annual \\
\hline 1993 & 5.69 & 3.54 & 2.93 & 3.07 & 4.07 \\
\hline 1994 & 3.04 & 2.87 & 4.77 & 2.07 & 3.36 \\
\hline 1995 & 3.16 & 2.33 & 3.14 & 2.91 & 2.75 \\
\hline 1996 & 2.76 & 3.49 & 3.70 & 3.17 & 3.20 \\
\hline 1997 & 3.08 & 3.06 & 2.82 & 2.15 & 3.06 \\
\hline $\begin{array}{l}\text { mean } \\
500 \mathrm{hPa}(\mathrm{dT})\end{array}$ & 3.55 & 3.06 & 3.47 & 2.67 & 3.29 \\
\hline 1993 & 3.38 & 2.76 & 3.23 & 3.34 & 3.59 \\
\hline 1994 & 3.34 & 2.08 & 1.96 & 3.18 & 2.68 \\
\hline 1995 & 4.18 & 1.78 & 4.92 & 4.80 & 3.91 \\
\hline 1996 & 3.44 & 3.07 & 3.44 & 3.08 & 3.76 \\
\hline 1997 & 4.20 & 2.73 & 3.15 & 3.06 & 3.36 \\
\hline \multicolumn{6}{|l|}{$700 \mathrm{hPa}(\mathrm{dT})$} \\
\hline 1993 & 3.58 & 3.46 & 4.32 & 3.63 & 4.24 \\
\hline 1994 & 3.87 & 2.79 & 2.65 & 4.00 & 3.24 \\
\hline 1995 & 4.45 & 1.98 & 4.58 & 3.80 & 3.91 \\
\hline 1996 & 4.25 & 3.12 & 3.65 & 4.00 & 3.85 \\
\hline 1997 & 4.76 & 3.15 & 3.40 & 3.52 & 3.91 \\
\hline mean & 4.18 & 2.9 & 3.72 & 3.79 & 3.83 \\
\hline \multicolumn{6}{|l|}{$850 \mathrm{hPa}(\mathrm{dT})$} \\
\hline 1993 & 4.66 & 3.98 & 5.71 & 3.83 & 4.91 \\
\hline 1994 & 5.28 & 3.30 & 3.60 & 4.64 & 4.20 \\
\hline 1995 & 4.96 & 2.07 & 4.52 & 4.57 & 4.26 \\
\hline 1996 & 4.41 & 3.58 & 3.77 & 4.72 & 4.05 \\
\hline 1997 & 4.70 & 4.55 & 4.37 & 4.86 & 4.61 \\
\hline mean & 4.8 & 3.5 & 4.39 & 4.52 & 4.41 \\
\hline \multicolumn{6}{|l|}{$1000 \mathrm{hPa}(\mathrm{dT})$} \\
\hline 1993 & 4.16 & 2.33 & 3.99 & 3.62 & 3.55 \\
\hline 1994 & 4.43 & 1.99 & 2.39 & 4.09 & 3.31 \\
\hline 1995 & 3.73 & 1.14 & 3.06 & 3.91 & 3.24 \\
\hline 1996 & 2.90 & 1.96 & 3.14 & 3.86 & 3.09 \\
\hline 1997 & 4.39 & 2.62 & 3.05 & 4.03 & 3.62 \\
\hline mean & 3.92 & 2.01 & 3.13 & 3.90 & 3.36 \\
\hline
\end{tabular}

\section{Material and methodology}

\subsection{Description of study area and data}

The air temperature and pressure height observations using the radiosonda sounding system at 00:00 GMT, between 1993 and 1997 at Goztepe (Istanbul: $40^{\circ} 55^{\prime} \mathrm{N}, 2^{\circ} 05^{\prime} \mathrm{E}$ ), have been analyzed. The study area (Göztepe Observatory) is at the transient region of two continents: Europe and Asia. It is under the effects of land-air-sea interactions. This contrast and temperature differences trigger a thermal turbulent structure of the atmospheric boundary layer.

Time variation of daily pressure height and standard deviations of air temperature and pressure heights up to the $300-\mathrm{hPa}$ pressure level have been analyzed in this paper. Standard deviations have been presented in the following sections. 


\subsection{Tools and methodology}

MATLAB and SPSS packet programs were used as a tool for the main objectives of this study (Aslan and Oguz, 1998; Aslan et al., 1997; Can et al., 2002).

\subsection{Continuous 1-D-wavelet}

The wavelet analysis is a great improvement in the analysis of atmospheric data, especially in studying the displacement characteristics of a moving structure (Meyer, 2000; Terradellas et al., 2001). The guide includes a comperative study of the windowed Fourier transform, the choice of an appropriate wavelet basis function, edge effects due to finite-length time series and the relationship between wavelet appropriate wavelet basis function, scale and Fourier frequency (Tokgozlu et al., 2002).

If function $\mathrm{f}(\mathrm{t})$ is continuous, has null moments, decreases quickly towards zero when $\mathrm{x}$ tends towards infinity, or when it is null outside a segment of $\mathrm{R}$, it is a likely candidate to become a wavelet. The family of shifts and dilations allows all finite energy signals to be reconstructed using the details in all scales. This property allows only continuous analysis. In the toolbox, the wavelet is usually associated with a scaling function. Wavelets, even $\mathrm{db} 2, \mathrm{db} 3, \ldots$, are defined by functional equations. The solution is numerical and accomplished by using a fairly simple algorithm. A 1-D analysis is based on one scaling function and one wavelet. A 2-D analysis (on a square or rectangular grid) is based on one scaling function and three wavelets. All the functions decay quickly to zero.

In the following sections $f(t)$ will be considered as pressure height or air temperature deviations from mean values. Let $f(t)$ be a function of time and that

$$
\int_{-\infty}^{\infty}|f(t)|^{2} d t<\infty
$$

The Fourier transform $F$ of $f(t)$ is defined as

$$
F(w)=\int_{-\infty}^{\infty} f(t) e^{i w t} d t
$$

A function $\psi(\mathrm{t})$ satisfying the following condition is called a continuous wavelet (Can et al., 2004):

$$
\begin{aligned}
& \int_{-\infty}^{\infty}|\psi(t)|^{2} d t=1 \\
& \text { and } \\
& \int_{-\infty}^{\infty}|\psi(t)| d t=0 .
\end{aligned}
$$

Higher order moments may be zero, that is,

$$
\int_{-\infty}^{\infty} t^{k} \psi(t) d t=0 \quad \text { for } \quad k=0, \ldots, N-1 .
$$

2.4 Viscosity coefficients and thermal conductivity

Usually the viscosity $\mu_{i}$ and thermal conductivity $\lambda_{i}$ are temperature dependent and are expressed in the following form:

$\lambda_{i}=A_{i} T^{b_{i}}$

where $\mathrm{A}_{i}$ and $\mathrm{b}_{i}$ are parameters determined from fitting the experimental results. The coefficients of viscosity $\mu$ and thermal conductivity $\lambda$ are computed from Dal Garno and Smith (1962):

$\mu=3.34 \times 10^{-7} T_{o}^{0.71}$,
$\lambda=6.71 \times 10^{-4} T_{o}^{0.71}$.

\section{Analysis}

\subsection{Analysis of pressure heights}

\subsubsection{Statistical analysis}

Statistical analysis of pressure height (h) with deviations at all levels is presented in Table 1. Maximum deviations (dh) are recorded at $1000 \mathrm{hPa}, 850 \mathrm{hPa}$ and $300 \mathrm{hPa}$ pressure levels in winter. Maximum pressure deviations are observed at $700 \mathrm{hPa}$ and $500 \mathrm{hPa}$ pressure levels in spring and minimum deviations are observed at all levels in summer. Maximum annual deviations for $300 \mathrm{hPa}, 500 \mathrm{hPa}$ and $1000 \mathrm{hPa}$ pressure levels are observed in 1997 and for 700 and $850 \mathrm{hPa}$ in 1993.

\subsubsection{Wavelet analysis}

In order to illustrate the relationship between small, meso and large-scale fluctuations on air pressure and temperature, time series of five years' worth of data were analyzed by using Continuous 1-D dB-level 3 wavelet.

Large-scale effects on pressure deviations at the $850-\mathrm{hPa}$ pressure level have been observed at the beginning of the first, third, fourth and fifth years (Fig. 1). Generally, the peak appears in the wavelet series of pressure disturbance in winter. Table 1 shows that amplitudes at the 500-hPa pressure level are almost two times greater than the values observed at the $850-\mathrm{hPa}$ pressure level. The deviations (higher amplitudes) of pressure values at $300 \mathrm{hPa}$ are higher than the deviation values recorded at lower layers.

\subsection{Analysis of air temperature}

\subsubsection{Statistical analysis}

Monthly maximum temperature deviations have been observed in spring or autumn between $1000 \mathrm{hPa}$ and $300 \mathrm{hPa}$ pressure levels (Table 2). If we compare the annual mean deviation values of monthly mean temperatures, the maximum values are observed between 850 and $300 \mathrm{hPa}$ in 1993 . For the $1000-\mathrm{hPa}$ pressure level the maximum value is observed in 1994. Minimum temperature deviations, in the 


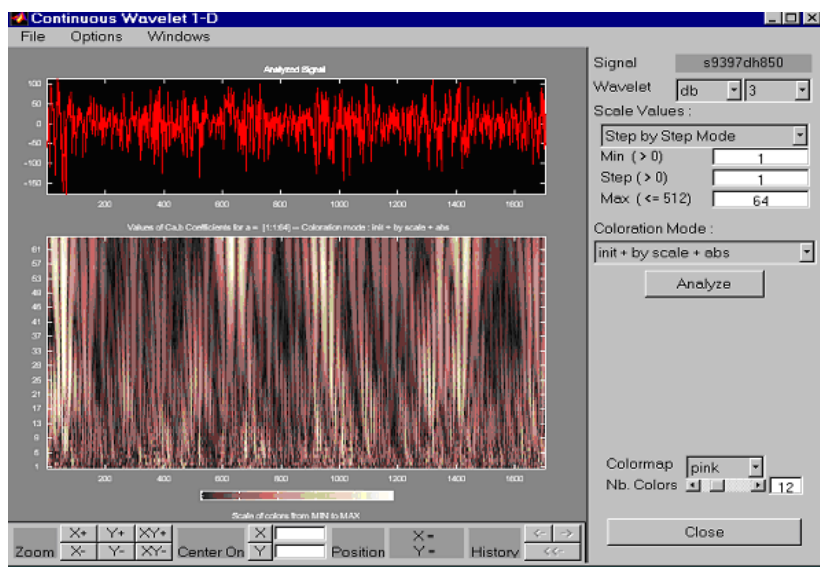

Fig. 1. Continuous wavelet 1-D analysis of the $850-\mathrm{hPa}$ pressure height deviations (Istanbul, 1993-1997).

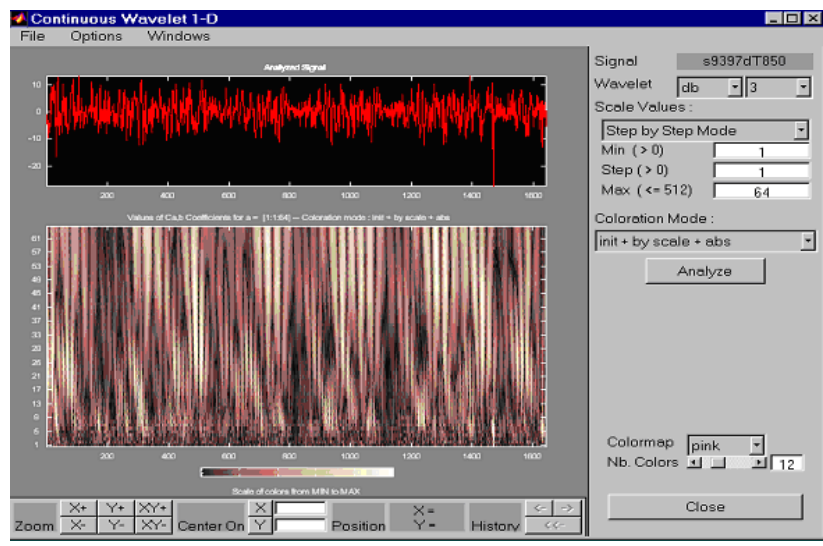

Fig. 2. Continuous wavelet 1-D analysis of air temperature deviations at the 850-hPa pressure level (Istanbul, 1993-1997).

other words weak gravity waves, have been observed between the 1000-500-hPa pressure levels in summer.

\subsubsection{Wavelet analysis}

Lower positive deviations have been observed at the 850hPa pressure level (Fig. 2). Air temperature series generally show a similar pattern in this period. Their wavelet transform modulus show a main peak at the 500-hPa pressure level, in the first period of 1995. Smaller deviations between 1994 and 1996 have been recorded at the 700-hPa pressure level. Large-scale effects are more effective on dT variations at this level in the second part of the period. Generally, small-scale fluctuations play a more important role on dT values at the 500-hPa pressure level in 1993.

\subsubsection{Analysis of thermal conductivity and coefficients of viscosity}

Daily variations of thermal conductivity and viscosity coefficients at the 850-hPa pressure height in 1997 are analyzed (Fig. 3). Conductivity values increase at the beginning of
Thermal Conductivity, 850hPa, 1997

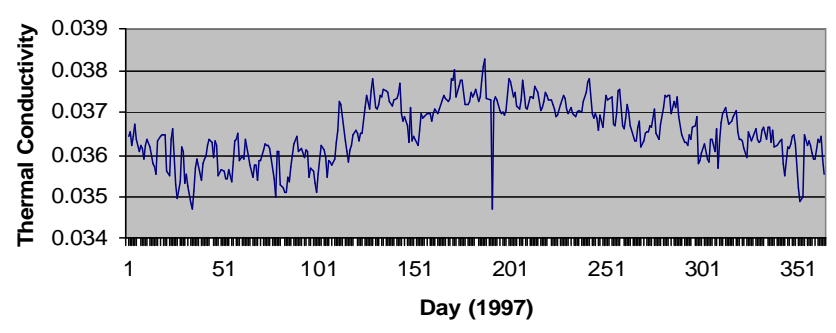

Fig. 3. Daily variation of thermal conductivity $(850 \mathrm{hPa}, 1997)$.

Table 3. El Niño and La Niña years in the observation period.

\begin{tabular}{rrrl}
\hline Year & Average SOI & $\begin{array}{c}\text { Following } \\
\text { Year }\end{array}$ & Label \\
\hline 1993 & -1.08 & $1993-1994$ & SE (Stronger El Niño) \\
1994 & -1.43 & $1994-1995$ & SE (Stronger El Niño) \\
1995 & 0.0 & $1995-1996$ & N (Neither) \\
1996 & 0.47 & $1996-1997$ & N (Neither) \\
1997 & -1.67 & $1997-1998$ & SE (Stronger El Niño) \\
\hline
\end{tabular}

spring. They show a slightly decreasing trend in the first part of summer when energy distribution decreases.

\subsection{Connections with El Niño and La Niña}

Table 3 shows El Niño and La Niña years in the observation period (World Climate News, 2003).

Small standard deviation of pressure heights correspond to weak gravity waves with low amplitudes. In 1995 (neither El-Niño, nor La-Niña) the lowest amplitudes of gravity waves have been observed in summer. Strong El-Niño effects increase the amplitudes of gravity waves in summer.

Higher temperature deviations have been observed in ElNiño years $(1993-1994,1997)$ at the 300-, 850-, 1000-hPa pressure levels. In 1995 and 1996 (neither El-Niño nor LaNiña) lower temperature values have been observed in these pressure levels.

Large-scale effects play an important role in temperature variation. It is concluded that higher temperature and pressure deviations from mean values at lower layers (in the vicinity of $850 \mathrm{hPa}$ pressure level), are observed in strong El Niño Years (1993, 1994 and 1997).

\section{Results and conclusion}

This is a case study which analyses daily variations of temperature and pressure deviations in the troposphere between 1993 and 1997. Wavelet analysis explains the sudden changes in parameters. It is also a useful tool for energy distribution analysis in the atmosphere.

The pressure height deviations increase above the $500-\mathrm{hPa}$ pressure level in the observation period. Between 1995 and 
1996 (Neutral Period: neither El-Niño nor La-Niña) the lowest deviations were observed around the $850-\mathrm{hPa}$ pressure levels. Similar structures between temperature, turbulence parameters and geo-potential height deviations have been defined at all pressure levels.

Acknowledgements. The authors thank O. Tüzün and O. Tascan for their support on this study. The authors acknowledge for their support from Istanbul Commerce University, Yildiz Technical University. The study has been supported by research foundation of Yildiz Technical University with project No. 21-01-01-02, 20012004. The authors also thank the referees for their valuable critics.

Topical Editor O. Boucher thanks P. Charton for his help in evaluating this paper.

\section{References}

Aslan, Z. and Oguz, O.: Time Variation of Gravity Waves in the Lower Atmosphere, IC/IR/92/22, Internal Report, 1998.

Aslan, Z., Okcu, D., and Kartal, S.: Harmonic analysis precipitation, pressure and temperature over Turkey, Il Nuovo CIMENTO, 20-4, 595-605, 1997.

Can, Z., Aslan, Z., and Oguz, O.: The variations of temperature, pressure and wind speed values: Effects on gravity waves, Il Nuovo Cimento, 25 C, 2, 137-145, 2002.

Can, Z., Aslan, Z., and Oguz, O.: One-Dimensional Wavelet and Reanalysis of Gravity Waves, Theme Issue of the AJSE on Wavelet and Fractal Methods in Science and Engineering, Part II, 29:2C, 2004.

Dal Garno, A. and Smith, F. J.: The thermal conductivity and viscosity of atomic oxygen, Planet. Space Sci., 9, 1-6, 1962.
Ding, F., Wan, W., and Yuan, H.: The Influence of Background Winds and Attenuation on the Propagation of Atmospheric Gravity Waves, J. Atmos. Sol. Terr. Phys., 65, 857-869, 2003.

Gao, W. and Li, B. L.: Wavelet Analysis of Coherent Structures at the Atmosphere-Forest Interface, J. Appl. Meteorol., 32, 1717$1725,1993$.

Isaac, M., Renuka, G., and Venugopal, C.: Wavelet Analysis of Long Period Oscillations in Geomagnetic Field Over the Magnetic Equator, J. Atmos. Sol. Terr. Phys., 66, 919-925, 2004.

Kutiel, H., Maheras, P., Türkes, M., and Paz, S.: North Sea-Caspian Pattern (NCP) - an upper level atmospheric tele-connection affecting the eastern Mediterranean-Implications on the Regional Climate, Theoretical Applied Climatology, 72, 173-192, 2002.

Meyer, Y.: The Role of Oscillation in Some Nonlinear Problems, School on Mathematical Problems in Image Processing, ICTP, SMR1237/4, 4-22 September, 2000.

Terradellas, E., Modales, G., Cuxart, J., and Yague, C.: Wavelet Methods: Application to the Study of the Stable Atmospheric Boundary Layer Under Non-Stationary Conditions, Dyn. Atmos., 34, 2-4, 225-244, 2001.

Tokgozlu, A., Siddiqi, H., and Aslan, Z.: De Noising and Analysis of Flight Measurements, Current Trends in industrial and Applied Mathematics, edited by: Manchanda, P., Ahmad, K., and Siddiqi, A. H., Anamaya Publishers, New Delhi, 47-67, 2002.

Torrence, C. and Compo, G. P.: A Practical Guide to Wavelet Analysis, Bulletin of the American Meteorological Society, 79, 1, 6178, 1998.

WMO: World Climate News, 23, 5, Switzerland, 2003.

Zink, F. and Vincent, R. A.: Wavelet Analysis of Stratospheric Gravity Wave Packets over Macquarie Island 1. Wave Parameters, J. Geophys. Res., 106, 10 275-10 288, 2001. 